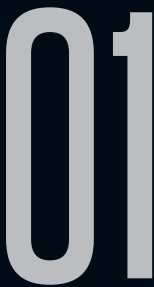

\title{
FUNÇÃO MAIÊUTICA DO ESTRANHO E DO REPULSIVO EM TEXTOS DE CLARICE LISPECTOR
}

Maria do Rosário Neto Mariano (UC)

Recebido em 10 jun 2015. Maria do Rosário Neto Mariano - Professora Auxiliar Aprovado em 09 out 2015. de Literaturas e Culturas Lusófonas e Francófonas, na Faculdade de Letras da Universidade de Coimbra. Doutora em Literatura Francesa (UC, 2013), Mestre em Literatura Comparada (UC, 1988). Membro integrado do Centro de Literatura Portuguesa (UC), participa em projetos de investigação apoiados pela Fundação para a Ciência e Tecnologia.

Resumo: A escritora Clarice Lispector manifesta uma capacidade surpreendente - e de modo particularmente expressivo nestes textos - para ir desvelando significações crípticas nos seres estranhos e/ou repulsivos do mundo natural, sobretudo nas suas espécies zoológicas mais distantes das caraterísticas e atributos que configuram a humanização.

Ao aprofundarem alguns desses elementos ctónicos - amiúde identificados com as forças infernais e demoníacas, e repudiados como imundos - as duas protagonistas destes textos abrem-se a uma metamorfose psicológica e espiritual que alterará para sempre a sua relação com o mundo criado. Assim, categorias/realidades como o estranho, o horrível, o repulsivo acabam por desempenhar uma função maiêutica ou configurar uma via iniciática para uma compreensão mais integral da Criação. 
Palavras-chave: Estranho; Repulsivo; Fascínio; Maiêutica; Metamorfose.

Compte rendu: L'écrivain Clarice Lispector manifeste une aptitude surprenante - et de façon tout particulièrement expressive dans ces textes - à dévoiler progressivement des significations cryptiques dans les êtres étranges et repoussants du monde naturel, surtout parmi les espèces zoologiques les plus éloignées des caractéristiques et qualités qui configurent l'humanisation.

Tout en scrutant profondément quelques éléments chthoniens - souvent identifiés aux forces infernales et démoniaques, et repoussés pour leur saleté physique et symbolique -, les deux protagonistes de ces textes s'ouvrent à une métamorphose psychologique et spirituelle qui changera pour toujours leur rapport au monde créé. Ainsi, l'étrange, I'horrible et le repoussant réussissent à réaliser une fonction maïeutique, c'est à dire à leur procurer une voie initiatique pour une compréhension plus intégrale de la Création.

Mots-clés: Étrange; Repoussant; Fascination; Maïeutique; Métamorphose.

De acordo com a dimensão psicossocial atribuída por Freud ao objeto fóbico, na sua modalidade monstruosa ou apenas repulsiva e temível, este configura e catalisa um conjunto considerável de angústias humanas, quer elas sejam identificáveis, indizíveis, ou até mesmo inabordáveis pelo pensamento.

Nesse sentido, o objeto fóbico cristaliza, simbólica e metonimicamente, tudo o que, na realidade física e psíquica, o sujeito individual (ou coletivo) não consegue processar através do pensamento analítico e reflexivo, passando a constituir um núcleo de estranheza e/ou repulsa no domínio sensitivo-emotivo, 
naturalmente acompanhado de medos com maior ou menor componente fóbica. Este tipo de fenómeno é, como se sabe, muito frequente relativamente a seres do mundo animal, sobretudo aqueles que evocam os espaços ctónicos, ou seja, os rastejantes, mormente se necrófagos, quer pertençam à categoria dos répteis, quer à dos insetos.

Não se trata de um medo proveniente de ameaça física de agressão ou morte - como aconteceria face a animais selvagens ou de grande porte - , mas de um medo-repulsa perante uma ameaça mais subtil: a de assimilação lenta e insidiosa por essa força entomológica arcaica (ou pré-histórica), inexpressiva ou radicalmente amorfa do ponto de vista emocional e sentimental, acompanhada de perda progressiva de caraterísticas humanas ou de "contaminação" pelo inumano, na sua versão mais cruenta e neutra, ou seja, sem parâmetros morais possíveis e, por conseguinte, passíveis de juízos éticos.

Esta é, sem dúvida, uma das perspetivas mais relevantes a partir das quais se pode construir uma leitura de certos textos de Clarice Lispector, em particular daqueles aqui em apreço: o romance A Paixão segundo G.H., e o conto Amor, incluído na coletânea Laços de Família. Com efeito, Clarice revela uma capacidade surpreendente para ir desvelando significações crípticas no repulsivo e no estranho do mundo natural, em particular as suas espécies entomológicas.

Assim, o olhar vítreo, milenar e inexpressivo da barata surpreendida no quarto de arrumações da personagem G.H., tal como a putrefação silenciosa dos frutos e a imobilidade da aranha predadora aguardando as suas presas perante o 
espanto da personagem Ana, constituem a seus olhos figurações temíveis do perigo de viver, das múltiplas ameaças que cercam o ser humano no seu périplo existencial. Porém, acima de tudo, estas personagens experienciam o medo atávico, ancestral que amiúde irrompe no ser humano confrontado com as forças cegas e implacáveis da Natureza; dir-se-iam configurar um poder de neutralizar o humano em toda a sua riqueza diferenciadora, ou pelo menos de desestabilizá-lo pela extrema angústia, seguida da parcial perda de identidade que acompanha os estados de intensa perturbação da consciência.

Recorde-se que as figurações da Górgona, na mitologia antiga, incarnavam o impensável da violência, da perversidade e da desumanização ou, por outras palavras, a dissolução do humano no monstruoso:

Trois soeurs, trois monstres, la tête auréolée de serpents en colère, des défenses de sanglier saillant des lèvres, des mains de bronze, des ailes d'or: Méduse, Euryale,Sthéno. Elles symbolisent l'ennemi à combattre. Les déformations monstrueuses de la psyché sont dues aux forces perverties des trois pulsions : sociabilité,sexualité, spiritualité. [...] On ne peut combattre la culpabilité issue del'exaltation vaniteuse des désirs qu'en s'efforçant de réaliser la juste mesure, l'harmonie (CHEVALIER \& GHEERBRANT, 1982, p. 381)

De modo similar, para G.H., a barata - e mormente o seu olhar inteiramente inumano - configura o seu horror pelo neutro como pré-história dos seres do reino animal, sendo ainda símbolo e metonímia da condição infernal, da sua treva sem compaixão nem esperança. O neutro significa em Lispector o radicalmente 
inumano, detentor de uma estranheza maior, mais sinistra e inacessível do que o desumano - ainda analisável e classificável nas categorias do perverso e do cruel.

Figurado sobremaneira no olhar e na linfa exposta do ortóptero, ele exerce sobre G.H. um efeito extremamente repulsivo, angustiante e paralisante, tal como a Górgona-Medusa petrificando os que ousavam olhá-la nos olhos:

Então abri de uma só vez os olhos, e vi em cheio a vastidão indelimitada do quarto, aquele quarto que vibrava em silêncio, laboratório de inferno. [...] A barata que enchia o quarto de vibração enfim aberta, as vibrações de seus guizos de cascavel no deserto. [...] Era um deserto que me chamava como um cântico monótono e remoto chama. Eu estava sendo seduzida. E ia para essa loucura promissora. Mas meu medo não era o de quem estivesse indo para a loucura, e sim para uma verdade - meu medo era o de ter uma verdade que eu viesse a não querer, uma verdade infamante que me fizesse rastejar e ser do nível da barata. [...] e, através da barata que mesmo agora revejo, através dessa amostra de calmo horror vivo, tenho medo de que nesse núcleo eu não saiba mais o que é esperança. (LISPECTOR, 2013, p. 47)

Deste modo se conjugam o inquietante, o estranho, o repulsivo, enquanto categorias estéticas que correspondem a sentimentos experimentados por D.H. - a protagonista e narradora autodiegética de um episódio de caráter iniciático simbolizado pela travessia do deserto; a resposta ao apelo da serpente-cascavel; o sabor infernal de uma certa dimensão do conhecimento; o horror da zoomorfose no sentido do imundo e do rastejante. Tais atributos correspondem a categorias arquetípicas 
e a espécies ctónicas do reino animal amaldiçoados em diversas Tradições sapienciais, e designadamente na Tradição judaicocristã. D.H., ela própria, o refere:

Eu me sentia imunda como a Bíblia fala dos imundos. Por que foi que a Bíblia se ocupou tanto dos imundos, e fez uma lista dos animais imundos e proibidos? [...] Eu fizera o ato proibido de tocar no que é imundo. [...] No meu mudo pedido de socorro, eu estava lutando era contra uma vaga primeira alegria que eu não queria perceber em mim porque, mesmo vaga, já era horrível: era uma alegria sem redenção, não sei te explicar, mas era uma alegria sem a esperança. [...] Ela seria tão proibida pela minha futura salvação quanto o bicho proibido que foi chamado de imundo - e eu abria e fechava a boca em tortura para pedir socorro (LISPECTOR, 2013, p. 56-58)

Se considerarmos, como David Roas, entre outros estudiosos da categoria estética do fantástico, que "lo fantástico se caracteriza por proponer un conflicto entre (nuestra idea de) lo real y lo imposible" (2011, p. 30), não podemos, em sentido estrito, considerar este romance de Lispector como um exemplar do fantástico literário, contrariamente ao que acontece, por exemplo, com A Metamorfose, de Franz Kafka, porquanto neste último o protagonista acorda, uma manhã, transformado em inseto rastejante, mantendo contudo as caraterísticas físicas e faculdades mentais próprias de um ser humano, ou seja, dois fenómenos através dos quais o real colide com o impossível.

Contudo, as categorias do estranho, do horrível e do repulsivo, paralelamente à do fantástico, são amiúde incluídas nas obras de arte (literárias, plásticas, cinematográficas), de modo a sugerir 
ou a postular o caráter anormal e falsamente tranquilizador da realidade. Por outras palavras, elas atuam como catalisadores da nossa atenção essencial, em geral obnubilada por hábitos mentais, esquemas rotineiros ou conformistas de pensamento, imagens arquetípicas e modelos coletivos de representação de pessoas, animais, elementos naturais, objetos, entre outras realidades constitutivas da nossa mundividência.

Por outro lado, estas categorias, à imagem do fantástico, têm em comum a natureza ameaçadora, inquietante e temível das suas figurações, desencadeando no sujeito diversos graus de medo físico e metafísico - para além da repulsa física ou moral, não necessariamente presente na categoria do fantástico (ROAS, 2011, p. 94-107).

Em A Paixão segundo G.H., tal como em Amor, a repulsa física ou o nojo explícitos são acompanhados de medo físico e metafísico, com variações de grau e de sintomatologia em cada um dos textos e, no primeiro, de acordo com o crescendo de aproximação - até à incorporação parcial do objeto-inseto mencionado. Esta sintomatologia traduz, num primeiro plano de análise, o horror ancestral do ser humano pelos animais atrás referidos (considerados "inferiores" e "malditos").

Aurel Kolnai, especialista neste domínio, considera que a repulsa por esses animais, associada à impureza ritual que lhe atribuem certas religiões, parece ser, contudo uma manifestação independente e primordial, fundamentada na sua assimilação ao imundo, à necrofagia e à fealdade, no que esta contém de mais estranho às categorias do humano, aproximando-se de algum modo da inumanidade disforme, temível e/ou sinistra do 
monstruoso. Referindo-se em particular aos insetos rastejantes, parasitas, vorazes e gregários, escreve o autor:

la relation - en partie apparente, en partie réelle - de ces animaux à la désintégration, à la décomposition ( ce qui est réel, c'est leur préférence habituelle pour les matières organiques pourrissantes; ce qui est illusoire - sans être négligeable -, c'est l'impression qu'ils font eux-mêmes partie de ces matières, qu'ils sont " engendrés" par elles, comme si leur activité grouillante et frénétique était un phénomène issu de la décomposition organique même); et surtout le caractère singulièrement "froid" de cette vitalité incessante [...] enfin, un trait d'agressivité sournoise chez le plus grand nombre de ces êtres vivants (KOLNAI, 1997, p. 61).

Paralelamente, este autor estabelece uma diferenciação muito relevante, e no plano psicanalítico deveras fundamentada, entre a repulsa/náusea e a angústia, face a objetos ou animais ameaçadores da integridade do sujeito, exposto aos mesmos nos planos sinestésico e psicológico.

Uma tal diferenciação revela considerável pertinência numa análise mais minuciosa das reações das personagens G.H. e Ana, protagonistas, respetivamente, do romance e do conto em questão. Atente-se, nesse sentido, ao excerto seguinte:

Quelque nombreux que soient les éléments de plaisir qui peuvent s'attacher secondairement à l'angoisse et au danger, dans sa nature profonde l'angoisse est parfaitement compréhensible sans faire l'hypothèse d'un désir mystique de ce qui est redouté. II en va tout autrement du dégout: sa logique interne comporte la possibilite d'une 
appréhension positive de l'objet - qu'il s'agisse de le toucher, de l'étreindre, de le consommer.[...] Psychanalytiquement parlant,le dégôut est plus ambivalente que l'angoisse (KOLNAI, 1997, p. 43-44)

Referindo-se a uma categoria muito próxima destas categorias e dos campos semânticos do repulsivo e do nauseante - o abjeto -, Julia Kristeva acentua igualmente esse traço de ambiguidade/ambivalência (1980, p. 17). Daí a ambivalência de sensações e sentimentos experimentados quer por Ana, face à pletora feroz e impassível evidenciada por certas espécies de seres vivos no Jardim Botânico, quer por G.H., perante a inumanidade radical, a silenciosa e ancestral resiliência, a figuração brutal do neutro configurada pela barata - tão monstruosamente exposta às sensações da personagem, quanto indiferente e opaca ao complexo de emoções e sentimentoslimite que vão eclodindo no ser humano que a confronta.

Assim sente Ana, mergulhada na fauna e na flora insólitas e de infernal beleza e exuberância:

E de repente, com mal-estar, pareceu-lhe ter caído numa emboscada [...] O banco estava manchado de sucos roxos. [...] No tronco da árvore pregavamse as luxuosas patas de uma aranha. A crueza do mundo era tranquila. O assassínio era profundo. E a morte não era o que pensávamos. Ao mesmo tempo que imaginário - era um mundo de se comer com os dentes [...] Como a repulsa que precedesse uma entrega - era fascinante, a mulher tinha nojo, e era fascinante. [...] A moral do jardim era outra. [...] estremecia nos primeiros passos de um mundo faiscante, sombrio, onde vitórias-régias boiavam monstruosas.[...] Era fascinante, e ela sentia nojo (LISPECTOR, 2013, p.22-23) 
Assim sente também G.H., ambígua prisioneira da realidade tenebrosa que vai emergindo sob os seus olhos, ao examinar a fisiologia da barata - ser arquetípico e ctónico, anterior a qualquer esboço de animal superior ou de hominídeo, mas também por isso exercendo na personagem (e voz narrativa) um horror pleno de fascínio pelo ínfimo monstro pré-histórico e sua funda inumanidade, na premonição de abertura a um mundo interdito, mas revelador de outras dimensões do Conhecimento e da própria Criação, aquelas mesmas que haviam outrora expulsado os seres humanos do Paraíso:

Na reverberação parada da luz do quarto, a barata era um pequeno crocodilo lento. [...] Nunca, até então, a vida me havia acontecido de dia. [...]e de manhã, ao abrir os olhos, o mundo continuava sendo uma superfície : a vida secreta da noite em breve se reduzia na boca ao gosto de um pesadelo que some. [...] Mas é que o inferno já me tomara, meu amor, o inferno da curiosidade malsã. Eu já estava vendendo a minha alma humana, porque ver já começara a me consumir em prazer, eu vendia o meu futuro, eu vendia a minha salvação, eu nos vendia (LISPECTOR, 2013, p.61)

Eis por que se, para Ana (a protagonista de Amor), a Natureza, a morte e o mundo não coincidiam com as imagens tranquilizadoras que a Cultura burguesa, sedentária e doméstica sempre the havia incutido em prol do bem-estar pessoal e familiar, para G.H., oriunda embora de um meio sócio-cultural idêntico, tornara-se indefetível transpor os muros dessa cidadela protetora, guardiã dos valores humanos-divinos estritamente associados ao Belo e ao Bem. 
No seu prefácio à supracitada obra de Aurel Kolnai, Claire Margat refere-se à reflexão que Walter Benjamin desenvolveu acerca da problemática do repulsivo e suas relações com o patológico e com a necessidade moral de superação do problema. Contudo, para Benjamin, ele não poderia ser efetivamente superado nem inteiramente recalcado, mas apenas sublimado por desiderato moral (KOLNAI, 1997, p. 14).

$\mathrm{Na}$ verdade, Ana operará em si mesma uma progressiva sublimação do belo-horrível que vivenciara no Jardim Botânico símbolo e metonímia do mundo que até então lhe fora oculto -, assombrada pelo misto de horror, vertigem e fascínio que esse outro lado da Criação nela desencadeara; mas, por outro lado, sentira uma premente necessidade moral de sublimar a repulsa e o horror, pois fora igualmente esse outro lado do mundo que em si mesma revelara a alma mais temerária, fogosa e arrebatada - aquela que, sem defesa nem medida, aceitaria "beijar o leproso" e seguiria o "chamado do cego", perdendo-se periclitante para a tranquila e trivial vida familiar que como um bordado diligentemente construíra:

Com horror descobria que pertencia à parte forte do mundo - e que nome se deveria dar à sua misericórdia violenta? Seria obrigada a beijar o leproso, pois nunca seria apenas sua irmã. [...] A vida do Jardim Botânico chamava-a como um lobisomem é chamado pelo luar. [...] Ao redor havia uma vida silenciosa, lenta, insistente. Horror, horror. [...] O que o cego desencadeara caberia nos seus dias? Quantos anos levaria até envelhecer de novo? (LISPECTOR, 2013, p. 24-25)

Como é notório, embora a personagem soçobre sob a pressão do medo físico e, sobretudo, metafísico que a estranheza 
do mundo nela fizera eclodir, não deixa, simultaneamente, de revelar uma extrema lucidez face ao poder maiêutico, nos planos existencial e espiritual, dessa mesma estranheza, ainda que aliada ao medo, à náusea/repulsa e ao horror.

Estes efeitos de ordem psicossomática, comuns em obras pertencentes a categorias estéticas como o fantástico, o repulsivo, o grotesco, o estranho, traduzem-se numa clara amplificação da mundividência psicológica, espiritual e humana das personagens envolvidas, constituindo em si mesma um verdadeiro processo maiêutico. Noutros casos, como acontece nos textos em questão, este processo tem origem mais propriamente numa epifania, enquanto manifestação do divino ou do demoníaco, quer a tónica seja colocada na luminescência, quer no sombrio ou tenebroso, na clarificação do mistério da Criação ou no seu adensamento.

É nesse sentido que o estranho e o repulsivo que estas personagens clariceanas sinestesicamente partilham (no caso de G.H. havendo mesmo ingurgitação de parte da matéria orgânica do inseto) atuam como forças entitativas que as expulsam do paraíso da ilusão e da inocência, ou seja, da beleza inócua e da ordem tranquila de um mundo idealmente eutópico, do qual o cruel, o horrendo e o repulsivo teriam sido providencialmente rasurados, de modo a preservar os valores estéticos e éticos propícios à paz da "fuga mundi", ou melhor, a uma certa forma de transcendência como via securitária para a salvação da alma e da existência.

Verifica-se, por conseguinte, um fenómeno contrário àquele que autores como Jean Fabre e Denis Mellier designaram por morale de la fuite e escapisme, relativamente a uma certa literatura do estranho e do fantástico, a qual configuraria 
uma efetiva estratégia de alienação do mundo real e da sua complexidade incómoda (MELLIER, 1999, p. 48-49).

Enfim, das dimensões excessivas do ser e do mundo, Ana se despede conscientemente como do próprio dia temível, soprando na chama da vela como quem previne um incêndio de proporções avassaladoras. Pelo contrário, G.H. persegue com determinação e horror a identidade neutra e pré-humana: a inexpressiva e radicalmente indiferente realidade matérica dos astros ou de seres vivos como as baratas - a sua impassibilidade gelada e cega ou a sua "crueldade" incolor e omnívora, respetivamente. Estas últimas, sobretudo, marcadamente impressivas na sua imunidade a quaisquer parâmetros humanos; tranquilas no "horror impunível" da própria entredevoração; inexoráveis em suas orgias necrófagas.

Essa terrível identidade, G.H. buscará enquanto vertente outra da Criação, aquela que misteriosamente fora desprovida de compaixão, de fé, de esperança, enfim, de todos os atributos constitutivos da humanização e próprios do Deus compassivo:

Este era então o outro lado da humanização e da esperança? No inferno, essa fé demoníaca de que não sou responsável. E que é a fé na vida orgíaca. A orgia do inferno é a apoteose do neutro. [...] E minha alma impessoal me queima. [...] Porque nesse fruir não havia piedade. Piedade é ser filho de alguém ou de alguma coisa - mas ser o mundo é a crueldade. [...] Só a misericórdia do Deus poderia tirar-me da terrível alegria indiferente em que eu me banhava, toda plena. [...] Eu caíra na tentação de ver, na tentação de saber e de sentir. Minha grandeza, à procura da grandeza do Deus, levara-me à grandeza do inferno. Eu 
não conseguia entender a Sua organização senão através do espasmo de uma exultação demoníaca. (LISPECTOR, 2013, p. 97-100)

Num ensaio consagrado à obra romanesca de Clarice Lispector, Maria Teresinha Martins afirma que a própria nomeação incompleta da personagem, efetuada somente por iniciais, "implicaria a ausência de substância do ser, não fosse G.H. o símbolo mítico de indefinição da personagem". Porém, por outro lado, "recriar o homem no nada e no tudo da linguagem, reconstruí-lo desde a raiz e desde a essência [...] é o esforço de extinguir as limitações da existência humana" (1988, p. 108-109).

Esta indefinição desumanizadora não corresponde, porém, ao sentido alienante, angustiado e essencialmente disfórico que Ihe é atribuído, em grande parte da Literatura Contemporânea, em que proliferam personagens anónimas ou perdidas de si mesmas e referidas apenas por iniciais - símbolo linguístico da sua fragmentação interior, com frequência irreversível.

No caso da obra de Lispector, e de modo muito relevante neste romance-clímax da criação da autora, à ação de dessubstanciar a pessoa no sentido de uma aproximação ao inumano corresponde o desiderato e a busca ativa de las rotinas consubstanciação com uma realidade ilimitada, essência que transcenda a das criaturas humanas em si mesmas. Para tal, G.H. renunciará à sua identidade individual e social, mas também à própria ideia de heroísmo ou de santidade, realizando então o "ato ínfimo" de se diluir no Não - ser do neutro - anteriormente estranho e horrendo e repulsivo - a fim de se abrir ao fluxo vital de tudo o que é, na 
magnânima indistinção do belo, do bem e de seus opostos: "Eu estava agora tão maior que já não me via mais. Tão grande como uma paisagem ao longe[...] Enfim eu me entendia para além de minha sensibilidade." (LISPECTOR, 2013, p. 140).

E assim se consuma, nos dois textos clariceanos aqui convocados, o desígnio maior que José Maria Merino atribuía e vaticinava para a Literatura:

Frente al sentimiento avasalador de aparente y común normalidade que esta sociedad nos quiere imponer, la literatura debe hacer la crónica de la extrañeza. Porque en nuestra existência, ni desde lo ontológico, ni desde lo circunstancial hay nada que no sea raro. Queremos acostumbrarnos a las rutinas más cómodas para olvidar esa rareza, esa extrañeza que es el signo verdadeiro de nuestra condición. (MERINO, 2004, p. 9)

\section{REFERÊNCIAS}

Bozzetto, R. (2001). Le Fantastique dans tous ses états. Aix-en-Provence: Public. de l'Université de Provence.

Chevalier, J., \& Gheerbrant, A. (1982). Dictionnaire des Symboles (2ed.). Paris: Robert Laffont.

Kolnai, A. (1997). Le dégout (O.Cossé, Trad.). Paris: Agalma.

Lispector, C. (s/d). Amor. In Laços de Família. Lisboa: Relógio d’Água. . (2013). A Paixão segundo G.H. (2ed.). Lisboa: Relógio d'Água.

Martins, M.T. (1988). OSer do Narrador nos romances de Clarice Lispector. Góias: Cerne. Mellier, D. (1999). L'Écriture de l'excès. Fiction fantastique et Poétique de la terreur. Paris: Honoré Champion.

Merino, J.M. (2004). Cuentos de los días raros. Madrid: Alfaguara.

Roas, D. (2011). Tras los límites de lo real. Una definición de lo fantástico. Madrid: Páginas de Espuma. 